Objectives: To describe the factors associated to an effective initiation of treatment after the baseline visit to our FLS.

Methods: Prospective observational study that consists of: 1) training of primary care physicians (GP), 2) capture of patients; 3) baseline visit: questionnaire including FRAX; 4) Bone densitometry; 5) patient education by a Nurse with special attention to adherence; 6 ) referral to GP with a report with management recommendations; those with multiple fractures or who require parenteral therapy were referred to rheumatology; and 7) follow-up by telephone survey to check whether the treatment was taking and confirmation of the prescription in the electronic records (both of which are necessary to consider an effective start of treatment). The variables included were: sex, age, type of fracture, use of previous bisphosphonate, type of prescribed treatment, prescribing physician and causes of non-adherence.

Results: Up to December 2017, the adherence of 887 patients with fragility fractures to whom a bisphosphonate or equivalent was prescribed, was recorded. Treatment was initiated in the following 3 months by $74 \%(n=656)$ of patients. The following variables were associated with the initiation of treatment: female sex, previous treatment with antiresorptives, prescription of denosumab vs bisphosphonate and treatment precribed by a rheumatologist vs GP (table 1). The causes of not initiating or withdrawing the treatment at 3 months are shown in table 2 . In the regression analysis, we found a significant association with the effective initiation of treatment with a pevious treatment with bisphosphonate $(p<0.01)$, initiation of treatment by the rheumatologist $(p=0.01)$ and prescription of denosumab vs bisphosphonate $(p<0.01)$

Abstract THU0477 - Table 1. Factors associated to start of treatment at 3 months ${ }^{*} \mathrm{p}<0,01$

\begin{tabular}{lcc}
\hline & $\begin{array}{c}\text { Patients that initiate } \\
\text { treatment }(\mathrm{n}=656)\end{array}$ & $\begin{array}{c}\text { Patients who did not initiate or } \\
\text { stop treatment }(\mathrm{n}=231)\end{array}$ \\
\hline Female/Male, $\mathrm{n}(\%)$ & $577(76) / 79(63)^{*}$ & $185(24) / 46^{37}$ \\
Age, mean (SD) & $76(9)$ & $76(9)$ \\
Type o fracture, $\mathrm{n}(\%)$ Wrist/Hip & $191(29) / 213^{32}$ & $71(31) / 68^{29}$ \\
$\begin{array}{l}\text { Previous treatment with } \\
\text { Bisphosphonate, } \mathrm{n}(\%) \text { Yes/No }\end{array}$ & $178(91) / 478(69)^{\star}$ & $18(9) / 213^{31}$ \\
$\begin{array}{l}\text { Prescription of Bisphosphonate/ } \\
\text { denosumab } \mathrm{n}(\%)\end{array}$ & $446(70,5) / 203(80)^{\star}$ & $186(29,5) /$ \\
$\begin{array}{l}\text { Prescription by Primary Care/ } \\
\text { Rheumatology, } \mathrm{n}(\%)\end{array}$ & $412(69,5) / 230(82)^{*}$ & $180(30,5) / 51^{18}$ \\
\hline
\end{tabular}

Abstract THU0477 - Table 2. Causes of no start or stop treatment, N (\%)

\begin{tabular}{lc}
\hline No prescription/suspension by GP & $115(50)$ \\
\hline Patient related causes & $93(40)$ \\
Patient does not want the treatment & $39(17)$ \\
Polipharmacy & $20(9)$ \\
Dont know/Did not visit the GP & $20(9)$ \\
Drug intolerance & $14(6)$ \\
Other causes & $23(10)$ \\
\hline
\end{tabular}

Conclusions: $74 \%$ of patients seen in the FLS start treatment within 3 months of the baseline visit. The factors associated with the initiation of therapy were prior antiresorptive treatment, denosumab prescription and initial prescription by the rheumatologist. The reason of non adherence in half of the cases is the GP's refusal to initiate or continue the FLS recommendation.

Disclosure of Interest: None declared

DOI: 10.1136/annrheumdis-2018-eular.4659

\section{THU0478 BEFORE AND AFTER MENOPAUSE, OSTEOPOROSIS RISK FACTORS ARE DIFFERENT IN WOMEN WITH RHEUMATOID ARTHRITIS}

J.-F. Chen, T.-T. Cheng, S.-F. Yu, Y.-C. Chen, C.-Y. Hsu, H.-M. Lai, F.-M. Su, B. Y.-J. Su, W.-C. Chiu. Division of Rheumatology, Allergy, and Immunology, Department of Internal Medicine, Kaohsiung Chang Gung Memorial Hospital and Chang Gung University College of Medicine, Kaohsiung, Taiwan, Province of China

Background: Rheumatoid arthritis (RA) is an autoimmune disease characterised by systemic inflammation, involving not only the juxta-articular bone erosion, but generalised bone loss[. ${ }^{1}$ Sex hormone activates RA disease activity and induced bone resorption, but hormone replacement therapy increases bone mass and density. The ambiguous role of sex hormone on bone remodelling is confusing in RA patients. Under the impact of sex hormone, risk factors for osteoporosis might be different at pre- and post-menopausal stage.

Objectives: To investigate the different clinical risk factors of osteoporosis in preand post-menopausal women with RA.

Methods: A cross-sectional study was performed during 2014 to 2017 , enrolling female participants fulfilled 2010 RA criteria[. ${ }^{2}$ We recorded demographic data, risk factors for osteoporosis and blood test. Osteoporosis is defined if one of hip, distal forearm, and lumbar spine bone mineral density less than -2.5 by T-score for post-menopausal women, or less than -2.0 by Z-sore for pre-menopausal women. Data was analysed by Student's $t$ test and Chi-square test for continuous and categorical valuables, respectively. Multivariate logistic regression was applied to detect association of osteoporosis and selected variables.

Results: A total of 451 participants were enrolled in the study, including 89 preand 362 post-menopausal women. The prevalence of osteoporosis is $14.6 \%$ and $36.7 \%$ for pre- and post-menopausal women with RA, respectively. At pre-menopause, low body weight is the only significant risk factors for osteoporosis, while old age, low body height, low body weight, positive anti-cyclic citrullinated peptide antibody (anti-CCP), previous fracture history, elevated white blood cell and platelet count, and lower calcium level are potential risk factors for post-menopausa women developing osteoporosis (table 1). Multivariate stepwise logistic regres sion analysis (table 2) showed body weight remains the leading risk factors in premenopausal women (Odds ratio[OR] $=0.84,95 \%$ confidence interval $[\mathrm{CI}$ $=0.76 \sim 0.94$, P-value $=0.002$ ), while body weight and previous fracture history are significant risk factors in post-menopausal women(body weight OR=0.91, 95\% $\mathrm{Cl}=0.88 \sim 0.94$, $\mathrm{P}$-value $<0.001$. previous fracture $\mathrm{OR}=2.03,95 \% \mathrm{Cl} 1.13 \sim 3.64, \mathrm{P}$ value 0.02 )

Conclusions: Risk factors of osteoporosis are different in pre- and post-menopausal women with RA. For pre-menopausal women, Low body weight is a leading risk factor, while low body weight and previous fracture history are important for post-menopausal women. Without protection of sex hormone, there are Potential roles of anti-CCP and white blood cell participating in osteoporosis pathogenesis and need more survey for confirmation.

\section{REFERENCES}

[1] Lems WF, Dijkmans BA: Should we look for osteoporosis in patients with rheumatoid arthritis? Ann Rheum Dis 1998, 57(6):325-327.

[2] Aletaha D, Neogi T, Silman AJ, Funovits J, Felson DT, Bingham CO, 3rd, Birnbaum NS, Burmester GR, Bykerk VP, Cohen MD, et al. 2010 rheumatoid arthritis classification criteria: an American College of Rheumatology/European League Against Rheumatism collaborative initiative. Ann Rheum Dis 2010,69(9):1580-1588.

Acknowledgements: Special thanks to Dr. Tien-Tsai, Cheng for his effort to establish the RA-GIOP database.

Disclosure of Interest: None declared

DOI: 10.1136/annrheumdis-2018-eular.1488

\section{THU0479 THE ANTIOSTEOPOROTIC TREATMENT IS SCARCE AMONG PATIENTS WITH VERTEBRAL FRACTURE REFLECTED IN THE RADIOLOGICAL REPORT: DATA FROM A FRACTURE UNIT-FLS}

A. Pons-Bas ${ }^{1}$, J. Rosas $^{1,1}$, M. Hernández ${ }^{2}$, C. Cano ${ }^{1}$, E. Ivars ${ }^{1}$, M. Lorente ${ }^{1}$, J. Hernández ${ }^{2}$, G. Santos-Soler ${ }^{1}$, A. García ${ }^{2}$, E. Salas ${ }^{1}$, H. Arcos ${ }^{2}$, J.M. SenabreGallego $^{1}$, J. Alvarado ${ }^{2}$, J. Jiménez ${ }^{2}$, C. López ${ }^{2}$, M. López ${ }^{2}$, A. Molinos ${ }^{2}$, B. Statti ${ }^{2}$, V. Miñanos ${ }^{2}$, J. Monteagudo ${ }^{2}$, X. Barber ${ }^{3}$, on behalf of AIRE-MB Group.

${ }^{1}$ Rheumatology Department, ${ }^{2}$ Radiology Department, Hospital Marina Baixa,

Villajoyosa (Alicante); ${ }^{3} \mathrm{COI}$, Miguel Hernández University, Elche, Spain

Background: A relevant number of patients with vertebral fracture (VF) do not receive specific treatment for osteoporosis and remain as invisible fractures. The objective of the Fracture Units-FLS is to detect patients with fracture, to perform an adequate diagnostic evaluation, initiate treatment and try to prevent new fractures.

Objectives: To know the characteristics of the patients and attitude of the referring service, in which the radiological report identifies the presence of VF.

Methods: Observational study carried out from January 1 to June 30, 2017, of consecutive patients in which the radiological report after performing simple radiology or CT, reflects the presence of dorsal, lumbar or both VF. The attitude of the service requesting the radiological test was reviewed 3 months after the radiological report.

The following variables were collected: general data of the patients (age, gender), the service requesting the imaging test (specialty, request from hospitalisation or ambulant, diagnosis and/or previous treatment for osteoporosis, attitude towards the FV) and the radiological test (type of test and location of the VF).

Results: 91 patients were included, of which $62 \%$ were women, with a mean age of $72 \pm 11.56$ years. In $46 \%$ of the patients, the image test was requested by one of the Internal Medicine Services (gastroenterology: 31\%, oncology-haematology: $17 \%$, rheumatology: $14 \%$, neumology: $12 \%$, cardiology: $10 \%), 36 \%$ by Primary Care Physicians, $15 \%$ from the Emergency Department of the Hospital and the remaining $2 \%$ from a Surgical Service.

In $77 \%$, the radiological test was given to ambulatory patients. In $56 \%$, the imaging test was simple radiology (chest $\mathrm{X}$-ray: $56 \%$, dorsal-lumbar spine: $41 \%$ and the 
remaining $4 \%$ bone series study) and $44 \%$ CT. In $61 \%$, the fracture was located in dorsal spine, in $28 \%$ in lumbar spine and the remaining $11 \%$ in the dorsal and lumbar spine. Previously, 44\% were diagnosed with osteoporosis and $38 \%$ were undergoing specific treatment (oral bisphosphonate: $23 \%$, bisphosphonate iv: $20 \%$, denosumab: $20 \%$, SERM: $8 \%$, PTH: $6 \%$ and only calcium +vitamin supplements D: $23 \%$ )

Three months after the identification of the VF, $66 \%$ did not receive specific treatment for osteoporosis, $11 \%$ were referred to Rheumatology (initiating treatment in all) and $3 \%$ to Traumatology. Three (3\%) of the patients had died and $2(2 \%)$ had moved away.

Conclusions: Despite being reflected in the radiological report, a significant number of patients with vertebral fracture do not receive antiosteoporotic treatment, 3 months later.

Acknowledgements: The study was supported with a research grant from the Association for Research in Rheumatology of Marina Baixa (AIRE-MB).

Disclosure of Interest: None declared

DOI: 10.1136/annrheumdis-2018-eular.4958

\section{THU0480 MULTI-DISCIPLINARY FRACTURE LIAISON SERVICE IN THE NORTH AREA OF GRAN CANARIA; 6 YEARS EXPERIENCE}

A. Naranjo ${ }^{1}$, S. Ojeda ${ }^{1}$, S. Rodríguez ${ }^{2}$, A. Saavedra ${ }^{1}$, F. Santana ${ }^{1}$, A. Molina ${ }^{1}$ A. Gonzalez ${ }^{3}$, N. Martin ${ }^{4}$, M. Afonso ${ }^{5}$, C. Dominguez ${ }^{5}$, I. Beirutti ${ }^{6}$, O. Suarez $^{7}$, T. Marrero ${ }^{7}$, C. Rodriguez-Lozano ${ }^{1} .{ }^{1}$ Rheumatology; ${ }^{2}$ Gerontology, Hospital Univ. Gran Canaria Dr. Negrin; ${ }^{3}$ Primary Care, Gerencia Gran Canaria; ${ }^{4}$ Rehabilitation; ${ }^{5}$ Analisis Clinicos; ${ }^{6}$ Orthopedic Surgery, ${ }^{7}$ Radiology, Hospital Univ. Gran Canaria Dr. Negrin, Las Palmas de Gran Canaria, Spain

Background: in March 2012 was implemented a FLS Unit coordinated by Rheumatology

Objectives: communicate the results of the unit in the 2012-2017 period.

Methods: Patients $>50$ years with fragility fracture. The program consists of: 1 ) training of primary care doctors (GP), 2) recruitment from the emergency room or admitted with hip fracture; 3) Bone densitometry; 4) patient education by a nurse; 6) report to GP with recommendations of managing; and 7) follow-up of persistence of treatment (telephonic survey plus prescription in the electronic records) at 3, 6, 12 and 24 months.

Results: The FLS has attended 1739 patients: mean age 73 y, 81\% women. The location of fractures was forearm $(32 \%)$, hip $(24 \%)$, humerus $(21 \%)$, vertebra $(10 \%)$ and other locations (12\%). Previous treatment with bisphosphonate $17 \%$, $10 \%$ of them at baseline.

After the baseline visit, $75 \%$ of patients were sent to GP and $25 \%$ to rheumatology. Treatment with bisphosphonate or equivalent was recommended to 1264 patients $(72 \%)$. Persistence of treatment (analysed at 3, 6, 12 and 24 months in $1,051,823,622$ and 351 patients, respectively) was $74 \%, 72 \%, 75 \%$ and $69 \%$, respectively

\begin{tabular}{lc}
\hline Risk factors (FRAX), $\mathrm{n}(\%)$ & \\
\hline Previous fracture & $323(18)$ \\
Parent's hip fracture & $190(11)$ \\
Glucocorticoids & $148(8)$ \\
Somking & $186(10)$ \\
Alcohol & $68(4)$ \\
Secondary Osteoporosis & $287(16)$ \\
BMl<18.5 & $31(2)$ \\
Rheumatoid arthritis & $40(2)$ \\
Bone Densitometry, $\mathrm{n}(\%)$ & \\
Normal & $159(13)$ \\
Osteopenia & $551(45)$ \\
Osteoporosis & $517(42)$ \\
FRAX, mean (DE) & $13,2(9)$ \\
Major Fracture & $6(7)$ \\
Hip Fracture &
\end{tabular}

Conclusions: Our FLS is effective in terms of beginning and persistence of antifracture treatment in the medium term.

Disclosure of Interest: None declared

DOI: 10.1136/annrheumdis-2018-eular.2361

\section{THU0481 \\ PHYSICAL PERFORMANCE FACTORS INFLUENCING GAIT SPEED IN PATIENTS SURGICALLY TREATED FOR OSTEOPOROTIC HIP FRACTURES}

B.R. Kim. JEJU NATIONAL UNIVERSITY HOSPITAL, Jeju, Korea, Republic of Ireland

Objectives: This study was undertaken to determine physical performance factors associative of gait speed in patients surgically treated for hip fractures.
Methods: Fifty eight patients (16 males and 42 females; average age 79.1 \pm 9.1 years) who underwent a hip surgery due to hip fractures participated in this study. Patients completed 10 metre walk test (10MWT) to assess gait speed. Additional physical performance tests included Timed up and go test (TUG), Berg balance scale (BBS), one repetitive maximum (1RM) of leg extension, leg curl, hip abduc tion of surgical and nonsurgical sides, and instrumental gait analysis for spatiotemporal parameters.

Results: In the bivariate analyses, postoperative 10WMT had a significant positive correlation with the postoperative TUG $(r=0.85, p<0.01)$, age $(r=0.57$, $p<0.01)$, swing phase duration $(r=0.35, p<0.01)$, gait cycle duration $(r=0.49$, $p<0.01)$ and significant negative correlation with the postoperative BBS $(r=-0.69$, $p<0.01), 1 R M$ of surgical leg extension ( $r=-0.35, p=0.01), 1 R M$ of nonsurgical leg extension ( $r=-0.40, p<0.01), 1 \mathrm{RM}$ of surgical leg curl $(r=-0.44, p<0.01), 1 \mathrm{RM}$ of nonsurgical leg curl $(r=-0.41, p<0.01)$, $1 \mathrm{RM}$ of hip abduction $(r=-0.32, p=0.02)$, cadence $(r=-0.53, p<0.01)$, stance phase duration $(r=-0.26, p=0.04)$. In addition, a presence of dementia was significantly correlated with 10WMT (44.2 s vs $22.4 \mathrm{~s}, \mathrm{p}=0.02)$. In the linear regression analyses, the postoperative TUG $(\beta=0.85, p<0.01)$ was a factor associative of the postoperative 10MWT.

Conclusions: This study revealed that the presence of dementia, the postoperative balance ability, muscle strength of surgical and nonsurgical legs were significantly associated with postoperative gait speed 1 month after hip surgery due to hip fractures. Therefore, these results could be importance in planning various postoperative rehabilitative programs to improve gait speed early after hip surgery due to hip fractures.

Disclosure of Interest: None declared

DOI: 10.1136/annrheumdis-2018-eular.1219

\section{THU0482 RELATIONSHIP BETWEEN MILD VERTEBRAL BODY DEFORMITY AND KELLGREN-LAWRENCE'S OSTEOARTHRITIS LEVEL WITH THE PREVALENCE OF NON-TRAUMATIC DORSAL AND LUMBAR BACK PAIN IN FEMALE PATIENTS WITH RISK OF OSTEOPOROTIC VERTEBRAL COLLAPSE}

C.A. Guillen-Astete, C. ljoán, J.R. Quiñones-Torres, M. Vázquez Díaz. Rheumatology Department, Ramon y Cajal University Hospital, Madrid, Spain

Background: There is a lack of information about the meaning of mild vertebral body deformities and its relationship with back pain. Many patients with this kind of wedges are sent to rheumatology clinics to assess the possibility to start treatment for secondary prevention of osteoporosis fractures.

Objectives: The present study aims to determine the relationship of the number of medical consultations due to dorsal or lumbar pain and two categorical variables: Presence or absence of mild vertebral wedge (Genant's first level of classification) and Kellgren-Lawrence's osteoarthritis classification levels I-II and III-IV

Methods: We conducted a retrospective follow-up of 1131 patients with and without mild vertebral body deformities along three years to compare the frequency of axial pain episodes assessed in emergency units and their chance to evolve to moderate or severe wedges.

Results: : In the group without deformities, the cumulative incidence of dorsal or lumbar pain episodes was $7.2 \%$ per year, and the incidence density was 7805 cases per 100 patients-year. In the group with mild deformities, the cumulative incidence of dorsal or lumbar pain episodes was $7.0 \%$ per year, and the incidence density was 7318 cases per 100 patient-year ( $p=0.77$ and 0.58 , respectively). We grouped patients according to their osteoarthritis severity. The cumulative incidence of dorsal and lumbar pain episodes along the period of observation, in patients with a spinal Kellgren-Lawrence's osteoarthritis degree I-II and III-IV were $19.8 \%$ (Cl95\% 12.10\%>27.49\%) and 31.5\% (CI95\% 18.27\%>44.72\%), respectively $(p<0.0001)$. The density of incidence for both groups was 6.18 cases per 100 patients-year and 11.3 cases per 100 patients-year, respectively $(p<0.0001)$. The difference in proportions of patients who developed a moderate or severe Genant's vertebral deformities was not statistically significant among patients with or without mild vertebral wedges.

Conclusions: Our results point that back pain incidence is not related to the presence of mild vertebral wedges but the severity of axial osteoarthritis. Also, the behaviour of starting a secondary osteoporosis prevention treatment after the detection of a mild vertebral wedge is not supported by our results.

Disclosure of Interest: None declared

DOI: 10.1136/annrheumdis-2018-eular.7333 